\title{
O SERVIÇO PÚBLICO FRANCÊS: EM BUSCA DE UMA ÉTICA PERDIDA ${ }^{1}$
}

\section{Jacqueline Morand-Deviller}

O tema dos serviços públicos é uma das questões mais enfrentadas pela jurisprudência e mais exploradas pela doutrina no direito francês, interesse suscitado pelo lugar central e determinante que o assunto ocupa neste direito e pela sua dimensão conceitual particularmente sedutora.

O serviço público "à la françaisè" está em crise, e não pela primeira vez. A crise atual é, sem dúvida, mais grave que as do passado, pois é geral, trazida pela borrasca da liberalização e da privatização. Ela afeta seus fundamentos, seu conteúdo, seus modos de gestão, enquanto que as outras crises eram nacionais e limitadas a uma melhor identificação do conceito e de seu campo de aplicação.

Essa crise tem como origem aignorância pela União Européia da noção de "serviço público", conceito finalista, demasiadamente abstrato, ao qual ela prefere a noção pragmática, operacional de "serviço de interesse econômico geral".

Toda crise é salutar, incita à reflexão sobre suas causas e anuncia um renascimento sobre novas bases. Essas breves observações dedicar-se-ão a rememorar as razões da expansão da noção de serviço público no direito francês, as quais são de ordem política, tanto de um ponto de vista ideológico: o mito do serviço público, quanto de um ponto de vista jurisprudencial: a estratégia do Conselho de Estado para estender o campo de sua competência (I). O mito sofreu em função desse sucesso desmedido, e sua dimensão ética se obscureceu, se é que não se perdeu, o que corresponde à situação atual (II). Porém, tal qual uma fênix que renasce de suas cinzas, a ética do serviço público não pode nem deve desaparecer, podendo ainda ser útil, em prol das sociedades e dos homens, como o foi em suas origens (III).

\section{I - Um mito fundador: ética e política}

O serviço público "à la française" tem uma dimensão finalista e operacional, pois corresponde, ao mesmo tempo, a um engajamento político ideológico e a uma tomada de posição da jurisdição administrativa, que poderíamos qualificar de "política jurisprudencial".

\section{$1^{\circ}$ - Solidarismo e socialismo}

A concepção francesa do serviço público é, antes de tudo, de ordem política. Inscrevese em uma aspiração republicana solidarista e apresenta-se como um "mito mobilizador",

\footnotetext{
Artigo originalmente publicado na França. Tradução livre de Bibiana Graeff Chagas Pinto, gentilmente revisada pela autora. Colaboraram também para a tradução os alunos Daniel do Amaral e Luciana Goulart Quinto, integtantes do grupo de pesquisa CNPq 'Mercosul e Direito do Consumidor", coordenado pela Prof. ${ }^{a} \mathrm{Dr} .{ }^{2}$ Claudia Lima Marques.
} 
segundo a expressão de um autor injustamente subestimado: Georges Sorel. ${ }^{2} \mathrm{O}$ propósito que sustentava Maurice Hauriou, opondo centralização e descentralização, a primeira mais "econômica e ágil", mas irresistivelmente superada pela descentralização, em termos de aspiração política, aplica-se de maneira bem adequada à oposição atual entre a lei liberal do mercado (que garantiria uma gestão mais "hábil e eficaz" e legitimidade tecnocrática) e uma necessidade de solidariedade social e de legitimidade democrática, incarnada pelo serviço público. A finalidade primordial do serviço público é democrática, deve responder não somente às necessidades, mas aos Direitos do Homem.

Para compreender a importância do serviço público na sociedade e no direito francês, é preciso procurar suas origens. A aparição da noção pode ser fixada com exatidão. Ela é descoberta no final do século XIX, forjada por juristas, mais precisamente por aqueles que representam, ao mesmo tempo, a jurisprudência e a doutrina do direito público: os membros do Conselho do Estado.

A partir de construções intelectuais de grande sutileza, eles perseguiram, incansavelmente, um objetivo preciso: solidificar o papel ainda frágil do Conselho de Estado enquanto juiz autônomo, assegurando-lhe um vasto campo de competência, através da ampliação do Direito Administrativo ${ }^{3}$. A razão de ser do serviço público é, em suas origens, o papel funcional e operacional que lhe é confiado pela jurisprudência.

Essa consagração só foi possível porque o conceito abraçava fortes aspirações sociais. No final do século XIX, vê-se a ascensão dos partidos socialistas e comunistas na Europa e do sindicalismo em torno das lutas em favor da justiça e da igualdade social. Reivindica-se direitos "reais", mas estes precisam de direitos abstratos para justificar sua consagração, e o serviço público passa a servir de elo. A doutrina universitária segue essa linha de pensamento, e uma "Escola do serviço público" faz a glória da Faculdade de Direito de Bordeaux e de seu decano, Léon Duguit. Esses avanços permitem uma redefinição do Estado e de seu papel: um Estado-Providéncia, fornecedor de prestações a serviço da solidariedade social, imagem mais persuasiva e legitimadora que a do Estado tradicional, que prescreve e regulamenta autoritariamente.

Embora o outro pilar sob o qual se apoia o Direito Administrativo, o critério da puissance publique (critério dos meios), conserve toda a sua importância, ele é substituído, e mesmo superado, pelo critério do serviço público (critério dos fins), apresentado como mais consensual, generoso, unificador. Através deste, o Direito se magnifica em dever, os privilégios

2 Georges Sorel (1847-1922), engenheiro civil convertido ao combate em favor da classe operária, apresentara em seu liv ro mais conhecido "Réflexions sur la ziolance" (1908), a greve geral como um mito suscetível de mobilizar a opinião pública em favor das causas sociais.

3 Ver "Le Conseil d"Etat et la fondation de la justice administratize au XIXème siècle", Textos reunidos e apresentados por Bernard Pacteau, PUF Léviathan, 2003

4 NT: A puissance publique é um dos critérios originários de identificação da competência da jurisdição administrativa na França. "Ao longo do século XIX, deduz-se uma orientação, sistematizada pela doutrina, que repousa na distinção entre os atos de autoridade, onde se manifestam as prerrogativas de poder público (puissance publique) da administração, e os atos de gestão, executados por ela nas mesmas condições que os particulares. Os primeiros requerem a competência do juiz administrativo, os segundos a do juiz judiciário. Essa distinção não perdeu todo o seu interesse, mas foi, no início do séc. XX, superada pela noção de serviço público, que, como será constatado posteriormente, a completa e a enriquece sem fragilizá-la." MORANDDEVILLER, Jacqueline. Cours de Droit Administratif, p. 16. 
se prolongam em responsabilidades. Alpha e omega do Direito Administrativo, o serviço público dá ao Estado coerência e unidade e traz à gestão pública uma presunção de eficácia econômica e social.

A noção declina-se no plural, e os seriç̧os públicos ilustram um amálgama entre estruturas e finalidade. Eles multiplicam-se, e esta profusão tem como origens, por um lado, uma mutação do Estado, que passa a se engajar cada vez mais na vida econômica (revolução industrial), nas causas sociais (luta contra as desigualdades) e nas questões culturais (desenvolvimento da educação e da cultura), e, por outro lado, um intervencionismo das coletividades locais ${ }^{5}$, inicialmente bastante restrito, na medida em que a falência da iniciativa privada devia ser constatada previamente, sendo esta, posteriormente, encorajada com o desenvolvimento das concessões de serviço público.

\section{2 - Uma política jurisprudencial}

No final do século XIX, o Conselho de Estado é, em direito, apenas o conselheiro do governo, encargo que lhe é confiado pela Constituição napoleônica do ano VIII, segundo a vontade do imperador de se cercar de um corpo de técnicos do direito de alto nível, como na tradição dos Legistas do Antigo Regime. Fora preciso um século para que ele conquistasse sua autonomia enquanto órgão julgador, a qual obteve do Legislador em $1872^{6}$. Se a justiça lhe era "delegada de fato", permanecia "retida de direito", podendo o ministro dar a última palavra. Um século a mais será necessário para que sua qualidade de alta jurisdição administrativa seja constitucionalizada (decisões do Conselho Constitucional de 1980 e 1987).

Essa sobrevivência do Conselho de Estado, apesar da fragilidade de seu estatuto de juiz $z^{7}$, é significativa da importância do lugar ocupado por uma instituição que é também uma especificidade francesa. Tornando-se orgão jurisdicional em 1872, o Conselho de Estado carecia ainda de precisão em relação a sua competência : era preciso definir o campo de aplicação do Direito Administrativo. Surge, então, o serviço público.

Um ano após a consagração da autonomia jurisdicional do Conselho de Estado, o primeiro julgado fundador interveio: a célebre decisão "Blanco", que, para decidir que a responsabilidade da Administração tem suas regras especiais e sua jurisdição particular, funda esta especialidade sobre o exercício de uma missão de serviço público.

Posteriormente, e de forma muito veloz, os "grandes julgados" se sucedem, vindos do Conselho de Estado e do Tribunal de conflitos, e o serviço público torna-se, a exemplo da puissance publique, o principal critério de reconhecimento do Direito Administrativo e de

5 NT: Na França, as coletividades locais, ou coletividades territoriais, são: os municípios, os departamentos, as regiões e os territórios.

6 Lei de 24 de maio de 1972, art. 9: "Le Conseil d'Etat statue souverainement sur les recours en matière contentiense administrative". O diplorna também cria o Tribunal de conflitos, composto em número igual de conselheiros de Estado e de conselheiros da Corte de cassação, encarregado de arbitrar os conflitos de competència entre as duas ordens de jurisdição.

7 Uma lei poderia ter suprimido seu caráter jurisdicional, enquanto que o seu status de consultor do governo fora, desde a origem, constitucionalizado

8 Tribunal des conflits, 8 de fevereiro de 1973: "L a responsabilité qui peut incomber à "Etat... par le fait des personnes qu' il emploie dans le sernice public.. a des règles spéciales qui varient selon les besoins du service et la nécessité de concilier les droits de lE tat avec les droits privés". 
competência do juiz administrativo, assim como dos contratos administrativos do Estado e das coletividades locais ${ }^{9}$. As conclusões do comissaire du Gouvernement ${ }^{10}$ da época são inequívocas: "Tudo o que concerne a organização e o funcionamento dos serviços públicos gerais ou locais... constitui uma operação administrativa, que é, por sua natureza, do domínio da jurisdição administrativa"11.

Não se poderia ser mais peremptório: como identificar a presença de um serviço público ou de uma operação administrativa? Os critérios de reconhecimento continuarão necessariamente vagos.

Mas o sucesso convoca ao excesso, e as "crises" assolam o serviço público, não em sua dimensão ideológica, que permanece sempre enraizada na mentalidade francesa, mas em sua gestão e seu papel funcional.

\section{II - O descomedimento: a ética perdida}

O rápido desenvolvimento do serviço público será, ao mesmo tempo, sua fraqueza. Demasiadamente invasivo e seccionado, esse pilar do direito público vê seus fundamentos abalados. Excessivamente autoritário, despoja-se de seus princípios primordiais, perde sua neutralidade e torna-se, segundo alguns, uma ameaça para as liberdades fundamentais, sobretudo econômicas. O colosso tem pés de argila. Reina como mestre, enquanto deveria reencontrar sua vocação primeira, de servidor.

\section{Colosso...}

A idade de outro do Direito Administrativo, na primeira metade do século XX, corresponde à idade de ouro do serniço público. É que estas duas noções são intimamente ligadas. O serviço público é a "pedra angular do Direito Administrativo", cujo domínio é por aquele estendido. Essa vocação repousa sobre o duplo caráter do serviço público, que é, ao mesmo tempo, abstrato - prestando-se unicamente a uma definição pouco precisa de atividade de interesse geral - e global - constituindo ao mesmo tempo finalidade, domínio de intervenção e estrutura administrativa, amálgama que incentiva as interações e o enriquecimento mutual. É porque as finalidades se desenvolvem que o campo de aplicação se amplia e que as estruturas se multiplicam. E esse crescimento conduz a uma situação artificial e paradoxal. O bloco monolítico, unificado em aparência, camufla uma extraordinária diversidade, e o ordenamento rigoroso em torno de um conceito, transformado em fição jurídica, cobre uma grande desordem.

9 Conseil d'Etat, 6 de fevereiro de 1903, "Terrieg" e 4 de março 1910, "Thérona".

$10 \mathrm{NT}$ : "Comissários da lei e do direito, os commissaires du Gouzernement exercem um papel próximo àquele assumido pelos representantes do ministério público frente às jurisdições judiciárias, cuja missão não é julgar, mas defender o interesse geral, 'a ordem pública' e de 'requerer a aplicação da lei'. Eles se exprimem por último nas audiências, pois a eles cabe fazer o resumo, a conclusão, do direito em causa. Assistem a deliberação mas não participam dos votos." MORAND-DEVILLER, Jacqueline. Op. Cit. p. 657 .

11 Conclusões de Jean Romieu sobre a decisão "Temrier" pré citada. 
A finalidade de interesse geral é, por natureza, de tal generosidade, que o serviço público não conhece quase nenhum limite. A elevação de uma atividade à categoria de serviço público segue a progressão das mentalidades e das estruturas sociais, e a "mutabilidade" é uma das leis do serviço. Em uma decisão de 1916, a atribuição da qualidade de serviço público é recusada para as atividades teatrais - mais perigosas para a "moralidade pública", como escrevera desastrosamente Maurice Hauriou, que o consumo do tabaco. ${ }^{12}$ A jurisprudência evoluirá rapidamente e, em nome do serviço público cultural e dos lazeres, chegará a reconhecer aos cassinos o exercício de uma missão de serviço público ${ }^{13}$, sem, no entanto, ir até o ponto de atribuir este "selo" nem às corridas de cavalo, nem aos jogos de sorte. A evolução avança sempre no sentido da expansão e, às vezęs, os meios justificam os fins, como no caso do reconhecimento de um serviço público para a concessão de espaços litorâneos a particulares, com o objetivo de lhes submeter à um procedimento concorrencial, embora a locação de colchões e as atividades de restauração destas concessões não correspondam propriamente a uma missão de serviço público. O critério é tão impreciso, que o "selo", às vezes, parece atribuído discrecionariamente, quase que por inadvertência.

Aliás, esse selo é dado generosamente a atividades fortemente marcadas pelo direito privado. Constata-se, simultaneamente, a proliferaşão dos serviços públicos industriais e comerciais de gestão privada e a freqüente assunção de missões de serriço público porpessoas privadas. A noção de parceria público-privado é tão velha quanto o nascimento dos Estados, e o velho sistema de concessão, durante muito tempo limitado aos trabalhos públicos e ao domínio público, adaptou-se facilmente ao serviço público, o que provocou a sua irredutível expansão, sendo imitado por outras estruturas privadas. ordens profissionais, federações esportivas... estas também chamadas a gerir serviços públicos. A predição feita no momento da identificação dos serviços públicos industriais e comerciais (SPIC) pelo célebre julgado do Tribunal de conflitos, de 22 de janeiro de 1921, dito "Bac d'Eloka"14, segundo a qual tais serviços continuariam sendo excepcionais, revelar-se-á completamente errônea.

Quando essa privatização ameaça atingir o domínio reservado ao Juiz administrativo, o Conselho de Estado reage com firmeza e, em 1955-1956, três "grandes decisões" dão, novamente, ao serviço público um papel primordial como critério de reconhecimento dos contratos administrativos ${ }^{15}$, do dominio público ${ }^{16} \mathrm{e}$ das obras públicas ${ }^{17}$, reforçando consideravelmente o campo de aplicação do Direito Administrativo e o papel da jurisdição administrativa. $O$ serviço público, assim revigorado, reencontrará uma nova juventude, sem que sua "dupla face", ou sua "face invertida" ${ }^{38}$ perturbem excessivamente.

12 Em suas notas sobre a decisão Conseil d'Etat, 1916, "Astruc", Maurice Hauriou, ilustre mestre de Toulouse, estima que o teatro apresenta o inconveniente "de exaltar a imaginação, de habituar os espíritos à uma vida factícia e fictícia, em grande detrimento da vida séria, e de excitar as paixões de amor, que são tão perigosas que as do jogo e da intemperança".

13 Conseil d'Etat, 5 de fevereiro de 1966 , "Ville de Royan"

14 Dando competência ao juiz judiciário para os "serrigos explorados nas mesmas condiçöes que um industrial ordinário", o Tribunal dos conflitos manifestava a hostilidade dos liberais da época à intervenção dos poderes públicos na atividade industrial e comercial e subentendia que esta intervenção devia permanecer excepcional. $O$ futuro desmentitia este prognóstico arriscado.

15 Conseil d"Etat, 20 de abril de 1956, "Epoux Bertin".

16 Conseil d'Etat, 19 de outubro de 1956, "Société Le Béton".

17 Tribunal des conflits, 28 de março de 1955, "Effimieff".

18 Essas expressões são utilizadas em relação aos estabelecimentos públicos, seja abusivamente qualificados de estabelecimento 


\section{$2^{\circ}$ - ... com pés de argila}

Esse descomedimento trouxe com ela os germes de uma degeneração, que fez com que a crise alcançasse todos os aspectos do serviço público, finalista, material e orgânico. $\mathrm{A}$ inutilidade funcional sucede, então, à anterior utilidade.

Nos anos 50, os mestres do Direito Administrativo eram unânimes em denunciar a importância da crise do Direito Administrativo francês ${ }^{19}$ provocada pela crise do serviço público: "Francamente, não se sabe mais ao que correspondem as noções ditas fundamentais do Direito Administrativo... quem pode dizer exatamente o que é um estabelecimento público, um organismo público, um serviço público?”, escrevia André de Laubadère em artigo publicado em 1952. E Marcel Waline foi além: "Alguns falam de declínio ou de crise da noção de serviço público (Rivero, Morange), e outros chegam a denegar qualquer alcance à essa noção (Vedel, Eisenmann), enquanto $M$. de Laubadère parece se declarar fiel à mesma, somente em respeito à memória de Duguit e Bonnard". ${ }^{20}$ Após a Segunda Guerra Mundial, a França se serve de um direito complacente para assegurar a dominação de operadores, de estrutura pública ou privada, controlados pelos poderes públicos e beneficiando de evidentes privilégios. Essa interdependência se constata também em nível local, como para as sociedades de economia mista de organização urbana, sustentadas indiretamente pelo orçamento municipal.

O fluxo e o refluxo das nacionalizações e das privatizações não causava nenhuma grande mudança $a^{21}$. Que a estrutura fosse pública ou privada, as grandes empresas públicas, tais como Electricité de France (EDF), Gaz de France (GDF), Société des chemins de fer français (SNCF), Air France, la Poste e as Télécommunications, categoria multiforme incapaz de se dotar de um estatuto, beneficiavam de vantagens certas, ameaçando inflectir os princípios tradicionais de igualdade e da neutralidade. As obrigações de serviço público se atenuam, enquanto as vantagens permanecem: ausência de riscos financeiros, pois o Estado ou as coletividades locais, em nome da continuidade do serviço, socorrem o operador quando necessário; situação confortável dos agentes que, sem serem funcionários, beneficiam da estabilidade de emprego e de vantagens de carreira e remuneração; rentes de situation ${ }^{22}$ na obtenção de mercados, do fato da ausência de competição.

Os princípios do serviço público e sua ética emaranham-se cada vez mais, e o que fazia sua grandeza tende a se atenuar. A noção banaliza-se a tal ponto, que sua presença não mais é suficiente para designar a competência do juiz administrativo, sendo preciso, além disso, que a gestão do serriço seja derrogatória do direito comum, ou seja, que revele a existência de prerrogativas de poder público: o bom e velho pilar tradicional retorna com toda a força, se

público administrativo (EPA) enquanto que se trata de um estabelecimento industrial e comercial (EPIC), seja, ao mesmo tempo, EPA e EPIC, segundo a natureza das missões exercidas.

19 A de Laubadère, "Réflexions sur la crise du droit administratif français", Dalloz, Chron. II, 1952, p. 5

${ }^{20} \mathrm{M}$. Waline, de jurisprudência, RDP 1954, p. 178

21 Três grandes ondas de nacionalizações se sucederam em 1936, 1945 e 1982. Em 1985, o setor público industrial e comercial nacionalizado compreendia 643 sociedades. Empregava $24 \%$ dos salariados, garantia aproximadamente $40 \%$ dos investimentos e 20\% das explorações. As privatizações passaram a ocorrer massivamente após as leis de 1986, 1993, 1997.

${ }^{22}$ NT: Uma rente de situation é uma vantagem obtida graças à ocupação de uma situação privilegiada ou estratégica. 
ousamos afirmá-lo, e a função unificadora do serviço público desaparece. A noção se despedaça, seu reconhecimento torna-se subjetivo. Procura-se a intenção da autoridade criadora do serviço, fiando-se em "indícios" 23 , necessariamente aproximativos.

Outra crítica desenvolve-se, pela qual esses privilégios que beneficiam os serviços públicos conduziriam à ineficácia da gestão pública, rigidezes burocráticas, rentes de situation, ausência de responsabilidade. Deveres públicos excessivos fragilizariam o poder público.

Ineficaz e dispendioso, o serviço público é também acusado de ser "liberticidd", sua expansão ameaçando a iniciativa individual e transformando os usuários em assistidos passivos e subjugados. As vantagens derivam ao ilícito, especialmente quando da conclusão das delegações de serviço público, e o intitulado de uma lei evoca expressamente o fato de corrupção ${ }^{24}$. A ética parece perdida.

Se a primeira crise tem como origem, por um lado, o imbróglio entre as estruturas e os regimes, misturando-se, de maneira desordenada, o direito público e o direito privado e, por outro lado, a maior incidência do direito privado na gestão dos negócios públicos, a segunda crise poderia ser mais longa e perigosa, pois não pode ser regrada "entre casa", ou seja, no âmbito francês.

A ofensiva vem da União Européia. Sabe-se que o conceito de "serviço público" é invocado apenas de maneira incidental no Tratado $^{25}$ e que é ignorado pelo projeto de Constituição européia. O conceito parece perigoso, em razão de sua abstração lírica e dos privilégios que ele outorga, os quais ferem os princípios da livre concorrência e da igualdade.

São visados sobretudo os grandes serviços em rede: energia, transportes, telecomunicações, dotados na França de uma posição monopolística e que, segundo as instâncias comunitárias, se adaptam mal às exigências do Tratado. O Direito Comunitário acolhe a noção de "seniços de interesse econômico geral", termo destinado a substituir o de serviço público, e que admite derrogações às regras da livre concorrência, justificadas pela missão particular destes serviços, mas estritamente limitadas e controladas.

O que resta, então, do conceito globalisante, unificador, mobilisador, ator, cujo direito francês podia se orgulhar? A Europa comunitária anunciaria o fim da concepçãa francesa do serniço público? Estaria o bloco europeu questionando o conceito ou apenas vilipendiando certas formas de ação pública que conduzem a abusos de posição dominante, as quais o recurso à finalidade de serviço público permitia camuflar? A ética do "serviço público à francesa" desapareceu definitivamente?

\section{III - O mito mobilizador: a ética reencontrada}

O serviço público deve reencontrar o élan ideológico que o sustentava em suas origens. Deve permanecer um conceito, uma fição jurídica cada vez mais necessária para o contrapeso à ausência de idealismo espiritual da competição econômica, que se instalou com vigor. Se

\footnotetext{
23 No julgado "Narcy", de 28 de junho de 1963, o Conselho de Estado realça três "indícios", que permitem a qualificação de um serviço público: uma missão de interesse geral, prerrogativas de poder público, um direito de controle da administração sob as modalidades de execução da missão.

24 Lei de 29 de janeiro de 1993, relativa à prevenģáo da comupgão e à transparência da vida económica e dos procedimentos públicos.

25 Artigo 73 do Tratado de Roma, em relação aos transportes. Posteriormente, não há outra referência ao "serviço público"
} 
toda ambição tem seus méritos, a do serviço público "à la française" é de outra ordem que a da ambição econômica, cujo sucesso se manifesta por balanços econômicos, onde a conquista de mercados impõe a qualidade dos produtos e dos serviços, a criação de empregos. A ambição econômica não pode se dar ao luxo - caro e arriscado demais - da gratuidade, da assistência desinteressada, da gestão da perda em nome do bem comum, luxo que o serviço público pode se permitir, com a condição de que não saia de seu território.

Mas embora suas finalidades sejam diferentes, o recurso a outras modalidades de gestão de boa performance se impõe em ambos os casos. $O$ modelo da gestão privada pode servir à causa do serviço público, e foi salutar que os privilégios, advindos da organização de serviços que de públicos só tinham o nome, tenham sido afastados pelas exigências comunitárias, obrigando a França a se inspirar do sistema da boa governança e da regulação.

\section{I - O bem comum contra a ditadura de interesses privados}

Exposto à influência de Bruxelas, o serviço público teve que se adaptar às exigências do liberalismo, escolha política e econômica. Esta escolha política, que se apoia essencialmente em objetivos econômicos, esse novo "mito", que faz repousar a paz sobre a prosperidade não é exempta de riscos. o da lei impiedosa do mercado, do peso dos interesses particulares, dos perigos para a igualdade e a solidariedade social. A economia uma ciência irremediavelmente relativa, do fato de sua variabilidade, enquanto que o direito precisa de estabilidade e de certezas, e a revolta contra um interesse geral posto "a todos os temperos" deve se acompanhar da desconfiança em relação a uma ditadura dos interesses privados. A revolta contra uma conceitualização global, julgada artificial em excesso, não pode excluir o receio de uma atomisação do direito e de uma desordem, bem mais temerosa que a primeira, em razão da multiplicação dos centros de decisão e do desenvolvimento das situações derrogatórias, em nome da diversidade.

$O$ direito necessita de ordem, e a ordem foi, durante muito tempo, aquela de um Estado moderno, que não tinha nenhuma razão de ser modesto, tal qual celebrava Jean Bodin em seus "Six liures de la République" (1576), ordem arranjada ao conceito de soberania, o qual republicano (respublica) - se afirmava contra a potestas do Imperador, a auctoritas do Papa e os mesmembramentos da Feudalidade. Nessa época, o Estado não é considerado como uma ameaça, mas como liberação. A ordem, no seio do Estado, repousa sobre poderes de coerção impostos aos indivíduos, e o primeiro critério do Direito Administrativo, o de puissance publique, é o herdeiro direto do imperium do Direito Romano; poder público à serviço da segurança pública, Estado que a Revolução sublima em Nação, Estado fator de liberdade, Estado protetor contra a ditadura dos interesses privados. Enfim, a ordem jurídica tem suas facetas multiformes: tanto pode ser obrigação para os cidadãos e liberdade para o poder, quanto liberdade para os primeiros e obrigação para o segundo. Essa questão está no centro dos debates atuais.

A promoção do serviço público é intimamente ligada a uma mudança de concepção do papel do Estado: quando o Estado-Providência alcança o Estado-Militar. Trata-se, nem mais nem menos, de um retorno à finalidade do "bem comum", caro à Aristóteles e à Tomás de Aquino, retomado posteriormente tanto pelas ideologias de direita, que pelas de esquerda, o que bem prova sua universalidade. $O$ interesse geral, que define a atividade do serviço 
público, é um componente desse bem comum, e isso não poderia ser negado pelos defensores do liberalismo. $O$ verdadeiro problema são a fronteira e os métodos a serem colocados em prática.

Nem tudo é bem comum, e nem tudo é serviço público. Não se trata de traçar limites aos serviços públicos tradicionais: Justiça, Defesa nacional, Polícia, Educação, Saúde, estes, que custam caro e rendem pouco. O que é preciso, é evitar uma invasão excessivamente larga da finalidade econômica às custas da finalidade política. Preservar os cidadãos da ditadura dos interesses privados, é os proteger contra as leis implacáveis da competição econômica: rentabilidade, lucro, competição, vitória contra os concorrentes, liberdade (preferida à igualdade). O serviço público não serve apenas a interesses econômicos, suas finalidades vão muito além. Ele nunca busca exclusivamente o lucro, e, mesmo, com muita freqüência, prioriza sua missão de assistência aos mais fracos e aos mais desprovidos, não por paternalismo benévolo, mas em nome de direitos idênticos para todos.

A questão que permanece é a definição do lugar efetivo do seriç̧o público original, o da não rentabilidade e dos grandes ideais democráticos. Os agrupamentos econômicos planetários são inelutáveis, pois sua ação gira exclusivamente em torno da adaptação ao fantástico e rápido desenvolvimento dos meios de comunicação e das trocas, da globalização e da identificação de nacionais, tornados cidadãos do mundo. Nessa ótica, os medos gerados pelas ameaças da ditadura econômica das multinacionais têm seus fundamentos. Estes receios e medos são os de um mundo governado pela economia. Trata-se de saber se, por um lado, a economia deve suplantar a política, e, por outro lado, se essa economia não deveria buscar suas outras finalidades, além das do lucro e da livre competição.

Os valores do venerado serviço público "à la française": desinteresse, solidariedade, igualdade, neutralidade, ainda são bastante necessários, a fim de reenviar os interesses econômicos - que, certamente, não deixam de ser importantes - aos seus territórios e de conservar territórios suficientemente vastos, onde outras "leis", além das econômicas, têm o seu lugar.

\section{2 - Regulação contra monopólios}

Reencontrada a ética tradicional do "serviço público", em sua dimensão finalista, ela apenas poderá prosperar se o aspecto orgânico e funcional da noção for ele mesmo revisto. Infiltrando-se por toda parte e perdendo sua identidade primordial, o serviço público, na França, tinha falhado em relação a seus próprios valores, conservando uma ambigüidade. Se, por um lado um lado, a situação de monopólio da maioria das grandes empresas públicas alegava a igualdade dos usuários frente às prestações do serviço, por outro, traía essa igualdade em relação a outros prestadores, em razão dos privilégios dos quais se beneficiava. Estes privilégios garantiam, dizia-se, a qualidade do semiço e o igual acesso de todos, questão essencial para julgar, no futuro, a experiência da liberalização.

O direito comunitário impõe atualmente a essas pessoas públicas, que se transformam cada vez mais em pessoas privadas, a concorrência, em perfeita igualdade com as empresas de outros membros da União Européia, na construção de uma política econômica comum. A abertura à concorrência dos grandes operadores de serviços em redes ocorreu progressivamente, 
com respeito às diretivas e regulamentos comunitários. A das comunicações interveio após as duas leis de 26 de julho de 1996 . Efetivou-se para a eletricidade através da lei de transposição de 10 de fevereiro de 2002, e, para o gás, pela lei de 3 de janeiro de 2003. A abertura à concorrência para os cliente profissionais é efetiva desde julho de 2004. Ela o será para os particulares em 2007. Electricité de France (EDF) e Gaz de France (GDF) deixaram seu venerável status de estabelecimento público para se tornarem sociedades de direito privado, pois o antigo estatuto de estabelecimento público é, em função do princípio da especialidade, um freio ao desdobramento de atividades. No que concerne aos transportes, as diretivas de 21 de julho de 1991 e de 19 de junho de 1993 impunham a separação das funções de gestão das infra-estruturas e da exploração dos serviços. Respondendo a estas diretivas, em 1997, uma distinção entre "Réseau ferré de France" (gestão de infra-estruturas) e SNCF (exploração dos serviços) foi elaborada. Finalmente, os semiços postais, tiveram seu estatuto modificado pela lei de 25 de junho de 1999, transpondo uma Diretiva de 1997, que define o conteúdo do serviço postal universal e precisa as condições de seu monopólio sobre o território nacional.

Fora a questão dos grandes serviços em rede, o conjunto das delegações de serviço público é submetido às obrigações de publicidade e de concorrência ${ }^{26}$, e a jurisprudência do Conselho de Estado adapta-se a essas novas condições.

O direito francês não teve dificuldade de se arranjar com a noção de "serniço de interesse econômico geral” (SIEG), que permite, a cada caso, a atribuição de uma exceção à aplicação das regras de concorrência; noção mais estreita que a de serviço público, pois concerne somente o interesse econômico, e cuja definição não é menos imprecisa... Ele também pode se adaptar à noção de "seniço universal", inventada nos Estados Unidos no início do século e retomada no Ato único de 1986. Esta noção designa um conjunto mínimo de serviços que devem ser colocados à disposição dos cidadãos ${ }^{27} \mathrm{e}$, por enquanto, diz respeito apenas aos serviços postais e à telefonia fixa.

O "serviço público à la française" pode, assim, reencontrar o brilho que o caracterizava há um século atrás, com a condição de se submeter a uma verdadeira reordenação; com a condição de por fim ao amálgama que havia obscurecido seus traços, distinguindo os critérios finalista, funcional e orgânico. A ética relaciona-se apenas às finalidades e às funções, e não há nada a ser suprimido quanto à exigência de desinteresse, neutralidade, igualdade, continuidade e adaptação. $O$ verdadeiro problema continua traçar uma fronteira entre as funções puramente econômicas e as outras, sendo que as primeiras são progressivamente influenciadas pelas segundas, como no caso de exigências sociais, ambientais, sanitárias. A economia não pode nem deve regulamentar tudo.

O critério orgânico tinha, há muito, perdido sua importância, já que a gestão dos serviços públicos industriais e comerciais já era fortemente privatizada e que era admitido que, freqüentemente, a melhor maneira de servir o interesse geral era apelar a gestionários

26 Ondonnance de 01/12/1986 e Lei de 08/02/1993, segundo as quais as regras da livre concorrència "s'appliquent a toutes les actizités de production, de distribution et de senice, y compris celles qui sont le fait des personnes publiques notanment dans le cadre de délégations de service public".

27 Três elementos o caracterizam: a universalidade (o conjunto dos cidadãos deve ter acesso ao serviço em todos os pontos do território), a qualidade do serviço e seu preço abordável. 
privados. Seu interesse renasce em se tratando de serniçospúblicos administrativos, com a tendência de se desenvolver partenariados públicos-privados, especialmente para a realização e depois para a gestão de equipamentos públicos: construções de prisões, de postos militares, de equipamentos hospitalares... O amálgama e os privilégios que resultam dessa situação não devem beneficiar apenas os interesses privados, abandonando os serviços públicos.

Em uma visão micro econômica e micro política do direito, é inevitável admitir que o conjunto dos interesses públicos tornaram-se mais ou menos particulares, o que significa constatar uma privatização do interesse público e a publicização do interesse privado. O interesse geral se apresenta, então, como o ponto de convergência entre os múltiplos interesses. Essa organização transversal e não mais piramidal de nossas sociedades impõe aos Estados uma nova maneira de gerir e de governar, recorrendo a métodos menos autoritários e mais consensuais. A regulação será, quando ela for possível, preferível à regulamentação, o Estado e as coletividades públicas procurarão mais convencer, do que obrigar, preferirão a arbitragem ao comando, e se empregarão à concertação, à persuasão, à pedagogia, à exemplaridade. E embora a regulação, que concerne sobretudo a política econômica, não tenha, vista de perto, um alcance jurídico particular, sendo apenas um novo comportamento, que nada retira dos métodos tradicionais, essa abertura ao debate democrático, essa busca paciente de conciliação entre interesses cuja extrema diversidade é admitida, é também um dos aspectos da ética reencontrada do serviço público. 